

The International Journal for Translation \& Interpreting Research trans-int.org

\title{
Cohesion in English to ASL simultaneous interpreting
}

\author{
Campbell McDermid \\ National Technical Institute for the Deaf \\ camnss@ rit.edu
}

DOI: ti.106201.2014.a05

\begin{abstract}
A study was done with 12 American Sign Language (ASL) - English interpreters to examine their use of cohesive devices while working simultaneously from English into ASL. Concern has been raised in the literature on spoken and sign language interpreters that practitioners create target texts that lack cohesion (La Bue, 1998; Langer, 2007; Sunnari, 1995). Halliday and Hasan's (1976) theoretical model of cohesion was used as a framework for this study. One aspect of cohesion was addressed, conjunctive devices.

The participants included seven novice interpreters, who had seven or fewer years of practice with ASL and who were recent graduates of an interpretation program. In addition, five experts took part who had more than two decades of experience as interpreters and who were all nationally certified. Three Deaf interpreter educators rated each interpreter's fluency in ASL, and found the experts created more fluent texts than the novices $(* * p=0.006)$. To understand why the Deaf raters found the experts more fluent, a number of basic language features in the interpreters' ASL target texts were compared but no significant difference was found in the number of signs created $(\mathrm{p}=0.57)$, the number of unique signs $(\mathrm{p}=$ $.074)$, signs per minute $(\mathrm{p}=0.57)$, the use of third person reference produced manually $(\mathrm{p}=0.46)$ or in the amount of information the interpreters omitted while interpreting $(\mathrm{p}=0.361)$. There was a significant difference in the interpreters' use of conjunctive devices ( $* * \mathrm{p}=0.007$ ), where the experts produced more of them.
\end{abstract}

Keywords: interpretation, cohesion, ASL, experts, novices

\section{Introduction}

What makes a simultaneous interpretation successful? This is a central question in the field of interpretation and many different models have been proposed to try and capture the concept of success. One facet that was repeatedly mentioned in sign language interpreting was that of the need for cohesion (Cerney, 2000; Coppock, 1992; Kelly, 2004; Russell, 2002; Winston, 1992; Zimmer, 1992). This was also emphasized by several authors on spoken language interpreting and translation (Baker, 1992; Blum-Kulka, 2000; Seleskovitch \& Lederer, 1995).

Educators believe that interpreters must be prepared to add information to target texts and create shifts in cohesion at times to make them accessible to the target audience (Blum-Kulka, 2000; Seleskovitch \& Lederer, 1995). In fact texts on interpreting and translation have devoted entire chapters to the subject (Baker, 1992; Larson, 1998). Blum-Kulka (2000) refers to this as the explicitation hypothesis, that texts must be made more explicit at times. At the same time it has been recognized that students of interpretation in particular may baulk at this as "they feel that they are being asked to be more logical than the original speaker" (Seleskovitch \& Lederer, 1995, p. 20).

Several studies have been done on spoken language interpreters that identified the explicitation of various aspects of a target text. Shlesinger 
(1995) found evidence of shifts in cohesion between English and Hebrew and in a later study again looking at interpreters working from English to Hebrew, Shlesinger and Ordan (2012) found an increased use of adverbs in their target texts. Gumul (2006) noted an increase in conjunctive devices in the work of interpreters between English and Polish, as did Becher (2011) in a corpus study of English to German translations. At the same time, few studies have looked specifically at features of cohesion in the target texts of ASL-English interpreters.

One study has been done on transliterators (Siple, 1995), interpreters who represent spoken English manually on their hands but who do not work between English and ASL. In this study the author found that the most frequent addition by the transliterators was cohesive devices (Siple, 1995).

However, the conceptual framework for cohesion did not disambiguate the various forms as will be described later under the theoretical framework for this study. Instead, the author (Siple, 1995) included both conjunctive devices and a number of features of reference under the rubric of cohesion, such as using one's fingers to represent a list of items or creating reference through the use of space, where different objects were established in different locations.

In a second study of sign language interpreters (La Bue, 1998), the author followed a model of cohesion similar to that proposed by Halliday and Hasan (1976). She outlined several examples of where the lack of cohesion in the interpreter's target text in sign language may have impeded two Deaf students' comprehension (La Bue, 1998).

Limitations of this study included a focus on only one interpreter who had a lack of formal training and the examination of the omission of cohesive devices but not the interpreter's ability to create cohesion.

In a third study, the author looked at the signed target texts of interpreters and defined cohesion as the use of "repetition, pronominal use, and certain discourse markers" (Langer, 2007, p. 49). In this study, the interpreters worked from English into either ASL or a pidgin form of sign language, Pidgin Signed English (Langer, 2007).

Again, the ability or propensity of interpreters to add cohesion was not addressed, but instead the omission of cohesive devices was the focus and was determined based on the comments of Deaf assessors. For example over half of the Deaf raters reported "difficulty in comprehension resulting from unclear or nonexistent transition markers" (Langer, 2007, p. 174). The inclusion of interpreters who attempted to work from English into a pidgin makes questionable the applicability of the results to interpreters working strictly from English into ASL alone.

\section{Research Questions}

Given the importance of cohesion in interpreted target texts, there is a lack of research on the abilities of ASL-English interpreters to create it in their interpreted target texts. Instead the research has focused on the omission of cohesive devices. Only one study has been done on the addition of cohesive devices (Siple, 1995) and at least two of the investigations to date (Langer, 2007; Siple, 1995) have included interpreters working into a form of signed English. The generalizability of these findings to ASL-English interpreters is thus uncertain. Absent has also been an empirical study looking at how an interpreter's use of cohesive devices might change with experience and enhanced fluency in ASL. With that context in mind, this study was designed to address the following research questions:

1) What differences in cohesion can be found in the target texts of novice and expert interpreters working simultaneously from their A language (English) into their B language (ASL)? 
2) What is the relationship between perceived fluency in ASL and the use of cohesive devices in the ASL target texts of sign language interpreters?

\section{Theoretical Framework}

Given that several authors (Baker, 1992; Blum-Kulka, 2000; Coppock, 1992; Siple, 1995) cited the model of cohesion proposed by Halliday and Hasan (1976), it was adopted as the theoretical framework for this study. In their model, Halliday and Hasan (1976) proposed two levels of cohesion, a broader or more text-based level of coherence and a local, lexico-semantic level of cohesion between sentences.

Both were created through "ties" from one or more aspect of the text to another typically endophorically, though there may have been ties to objects in the immediate environment or situation, referred to as exophoric reference (Halliday \& Hasan, 1976). Such ties gave a text its texture (Halliday \& Hasan, 1976). Zimmer (1992) described both "external" and "internal" coherence (p. 86), perhaps another means of differentiating coherence (external) from cohesion (internal).

Briefly and to differentiate the two, coherence is described as the structure of texts, such as a theme / rheme organization (Halliday \& Hasan, 1976). It is a more abstract level of meaning making to accommodate a potential reader's preference or orientation (Blum-Kulka, 2000). In dialogic texts, this has been described as "alignment towards one's interlocutors" (Zimmer, 1992, p. 87) to achieve successful communication. Aspects of coherence include rhetorical style (Blum-Kulka, 2000), register (Zimmer, 1992) and the function of a text (Coppock, 1992).

Unlike the broader concept of coherence, cohesive ties are created at a more local level, between sentences through the use of "reference, substitution, ellipsis, conjunction, and lexical cohesion" (Halliday \& Hasan, 1976, p. 4).

To be cohesive, for example, a text must make use of referencing between items in the text (endophoric) and make use of third person pronouns (for example, he, she, it, they) and includes "personals, demonstratives and comparatives" (Halliday \& Hasan, 1976, p. 31).

Reference to something external to the text (exophoric) or to the speaker and addressee (first and second person) is not considered cohesive, as these individuals are present in the context of the situation (Halliday \& Hasan, 1976).

Substitution is another means of creating cohesion. Briefly it entails the endophoric replacement of a noun/noun phrase, verb/verb phrase or clause with the use of words such as "so" (as in "I think so."), "one/ones" ("I want the blue ones."), "not" ("I hope not."), "do" ("Yes I did.") and "same/likewise" ("I suggest you do the same.") (Halliday \& Hasan, 1976). These typically do not substitute exactly for an earlier noun, verb or clause but instead indicate something similar.

Ellipsis, the next form of cohesion according to Halliday and Hasan (1976), is simply the act of substituting by zero.

The fourth means of creating cohesion is referred to as "lexical." It entails the repetition of a word in a text, the use of a synonym of some type, or the inclusion of words that typically collocate with each other (such as salt and pepper, black and white, government and politics, etc.) (Halliday \& Hasan, 1976).

Given the complexity of Halliday and Hasan's (1976) model, the decision was made to focus on one aspect of cohesion in this study, and that was conjunctive devices. To be cohesive, conjunctive devices must conjoin two independent sentences (Halliday \& Hasan, 1976) and Fraser's (1999) model was adopted, where conjunctive devices included "conjunctions, 
adverbs or adverbial phrases, and prepositional phrases" (p. 931). In English this would include the coordinating conjunctions, "for," "and," "nor," "but," "or," "yet," and "so" (FANBOYS).

Examples of conjunctive adverbs or adverbial phrases in English are "as a result," "therefore," and "consequently." Examples of prepositional phrases that function cohesively include "as a consequence," "in particular," "after all," "in contrast," and "on the other hand" (Fraser, 1999, p. 944).

Some of the above mentioned conjunctive devices also function as discourse markers, or what Halliday and Hasan (1976) referred to as continuatives. They gave examples of continuatives including, "now, of course, well, anyway, surely, after all" (Halliday \& Hasan, 1976, p. 268) and "anyhow, at any rate" (p. 270). Other examples from the literature include "because, and, then" and expressions like "hey" and "aha" "therefore, so, after all, and moreover" (Jucker, 1993, p. 436).

According to Fasold and Connor-Linton (2006), discourse markers "indicate how what someone is about to say - often at the beginning of a spoken utterance - fits into what has already been said and into what they are about to say next." (p. 178).

Several authors such as Matei (2010), however, noted that they can be "devoid of semantic meaning" (p. 119) in relation to what was said and as such do not contribute to the propositional meaning of the utterance (Fraser, 1999; Jones, 1992; Jucker, 1993) or its truth-value (Jucker, 1993).

There is much debate about the nature of discourse markers, ranging from a formalist view which looks at their impact on an utterance's truth conditions, a functional view which looks at how they function, and a cognitive view - that holds they represent an interlocutor's thinking process and signal "hesitation markers" and "interjections" that may "indicate the sudden recognition of information" (Matei, 2010, p. 121).

Not surprisingly, they have been described as "polyfunctional" by a number of authors (Jucker, 1993; Matei, 2010), which is believed to be one of the few things agreed upon (Fraser, 1999; Jucker, 1993; Matei, 2010). This study adopted a functional view, and so discourse markers were not seen as cohesive if they were used for the following purposes:

- $\quad$ to signal involvement or attention (Matei, 2010)

- $\quad$ to show a speaker's affect or emotional response (Fraser, 1999; Jucker, 1993; Matei, 2010)

- $\quad$ to suggest doubt in what was said or was to be said (Jucker, 1993)

- to mitigate face threats (Jucker, 1993) or as an attempt to "repair a damaged conversation" (Mey, 2001, p. 148).

- $\quad$ to indicate delay or hesitancy (Jucker, 1993)

- to verbalize an aspect of the speaker's cognitive process (Mey, 2001)

Instead, to be considered cohesive they had to conjoin two independent clauses or sentences (Fraser, 1999) and perform one of the following functions:

- $\quad$ to connect sections of text (Matei, 2010)

- $\quad$ to indicate shared ground (Matei, 2010)

- $\quad$ to put limitations on what was relevant (Fraser, 1999; Matei, 2010)

- $\quad$ to help the listener interpret utterances (Matei, 2010)

- $\quad$ to mark boundaries in the discourse (Matei, 2010) and signal topic changes (Fraser, 1999; Jucker, 1993)

- $\quad$ to show a comparison or contrast (Fraser, 1999)

- $\quad$ to signal a "quasi-parallel relationship" (Fraser, 1999, p. 948)

- $\quad$ to elaborate on or clarify meaning (Fraser, 1999)

- to constrain inferred relationships (illocutionary force) between two utterances (Jones, 1992; Fraser, 1999) 
It was suggested that discourse markers could occur sentence medial or final (Fraser, 1999) and thus move within a sentence (Jones, 1992), but this study adopted Schiffrin's (1987) earlier theory that discourse markers were sentence initial. In addition, as a meta-comment on the relationship of the conjoined sentences, they could be optional or detachable without making the sentence sound ungrammatical (Schiffrin, 1987). At the same time, their omission would probably cause native speakers to deem "the texts unnatural" (Jones, 1992, p. 127).

\section{ASL Conjunctions}

Having identified conjunctive devices in English, we next look at conjunctive devices in ASL and specifically conjunctions and discourse markers. A review of the literature showed that they included the following (in alphabetical order):

AND (Bailey \& Dolby, 2002)

ANYWAY (Humphries, Padden \& O'Rourke, 1980)

BUT (Bailey \& Dolby, 2002; Valli \& Lucas, 1995).

HAPPEN (Fischer \& Lillo-Martin, 1990; Humphries, Padden \&

O'Rourke, 1986)

HIT (Humphries, Padden \& O’Rourke, 1980)

FIND (Humphries, Padden \& O'Rourke, 1986; Scheetz, 2009)

FINISH (Fischer \& Lillo-Martin, 1990; Humphries, Padden \&O'Rourke, 1980; Janzen, 2007; Quigley \& Paul, 1984).

FOR-FOR (Wilbur, 1994)

FRUSTRATE (Humphries, Padden \& O’Rourke, 1980),

MEAN (Humphries, Padden \& O'Rourke, 1980)

OR (Bailey \& Dolby, 2002; Siple, 1995; Valli \& Lucas, 1995).

PLUS (Valli \& Lucas, 1995)

SO (Bailey \& Dolby, 2002) or the loan sign S-O (Kelly, 2004)

SUCCEED (Fischer \& Lillo-Martin, 1990)

SUPPOSE if in medial position between to complete clauses (Fischer \& Lillo-Martin, 1990)

UNDERSTAND, (Fischer \& Lillo-Martin, 1990; Valli \& Lucas, 1995)

WRONG (Fischer \& Lillo-Martin, 1990; Humphries, Padden \&O'Rourke, 1980), and

WHY (Humphries, Padden \&O’Rourke, 1980; Wilbur, 1994),

Siple (1995) noted the use of the sign MAYBE to represent OR, and also the sign NEXT (THEN) initialized with the letter "O" to indicate "or" (p. 63). However, Davidson, Caponigro and Mayberry (2009) suggested that the disjunct OR was "not typically marked with a manual sign" (p. 2) in ASL.

Several discourse markers in ASL were also described in the literature, including NOW (Hoza, 2011: Roy, 1995) and KNOW-THAT or KNOW (Baker-Shenk \& Cokely, 1980; Kelly, 2004). Other markers include HEY (Baker-Shenk \& Cokely, 1980; Hoza, 2011) and WELL (Baker-Shenk \& Cokely, 1980; Conlin, Hagstrom \& Neidle, 2003; Hoza, 2011; Winston \& Monikowski, 2003). Kelly (2004) listed INFORM-YOU, ANYWAY, FINE, NEXT, PUSH-ASIDE and O-K as well.

Not all discourse markers act cohesively. The sign HEY was historically seen as an attention getting device or conversational opener but could also serve as a warning, a personal interjection, a way to reduce face-threats or a means of mitigating potentially impolite behaviour (Hoza, 2011). In these functions, HEY would not add propositional content to an utterance, and so would not be considered cohesive.

The sign for SO, which looks similar to the sign WHAT except the signer's hands move forward, was also identified in the literature as a discourse marker sometimes translated into English as WELL (Baker-Shenk 
\& Cokely, 1980; Hoza, 2011; Morford \& MacFarlane, 2003). It is a commonly used sign in ASL according to Morford and MacFarlane (2003), who looked at only spontaneous samples of language use in 27 different signers on both commercially produced videotapes and videotapes from other research projects the authors initiated. They ranked it $14^{\text {th }}$ on a list of the most frequently used signs (Morford \& MacFarlane, 2003).

The non-cohesive functions of WELL as a discourse marker, given the definition adopted by this study, included the role of "a hedge, a filled pause, and an indefinite particle... and a turn-taking regulator" (Hoza, 2011, p. 86) or to connote some degree of uncertainty (Conlin, Hagstrom \& Neidle, 2003). Some of these functions are shared by the English "well" and some are not.

WELL or SO is cohesive, however, if it acts as a conjunction as suggested by Bailey and Dolby (2002) or "as an indicator of a footing shift, a coherence device" (Hoza, 2011, p. 86). In Baker-Shenk and Cokely's (1980) text on ASL, the English gloss WELL is used in frequent examples that represent these different functions. The following is a simplified example where the authors translate the sign WELL as the English "so":

ASL : [...] ME "WELL" NOTICE-TO-lf SHOE-lf ME me-PICK-UP-shoe, "open window" - cntr me-THROW-shoe-AT-cats CAT "cats suddenly scatter away". English Translation: "[...] so I picked it [shoe] up, opened the window, and threw it at the horde of cats." (Baker-Shenk \& Cokely, 1980, p. 307)

\section{Determining Fluency}

As this study attempted to explore the relationship between perceived facility in ASL and cohesion, a protocol was needed to determine fluency. As suggested in the literature (Roy, 1987), fluency was evaluated by a target language audience. Robinson (1997) characterized such an approach as a "“reader-response" (p. 107), and one means of achieving this, according to Cokely (1992), was by giving the audience a cloze task.

The Association of Visual Language Interpreters of Canada has adopted a similar approach, where the videotaped target texts of candidates for national certification are first rated by Deaf assessors to determine their ASL fluency (Russell \& Malcolm, 1992). Some researchers have also used samples of interpreted target texts to describe changes in fluency in second language users (Napier, 2005; Rudser, 1986) or to compare native to nonnative signers (Davis, 2003).

A popular protocol for assessing ASL fluency is the Sign Communication Proficiency Interview (SCPI) or the ASL Proficiency Interview (California State University Northridge, 2007; Madsen, 2001; Newell \& Caccamise, 2007). On the SCPI, there are six levels, ranging from "no functional skill," "novice," "survival," "intermediate," "advanced," to "superior" (Newell \& Caccamise, 2007, p. 9). Similar descriptors and levels were used in the construction of the scale adopted by this study (see Appendix B - ASL Fluency Scale).

While the SCPI has not been normed on samples of interpreted texts (Desrosiers, 2001) it has been used to screen educational interpreters (Burch, 1997; Desrosiers, 2001). A significant and positive correlation was found in one study between the interpreters' SCPI scores and their ratings on an interpreter performance test (Burch, 1997). There was also evidence that untrained raters, individuals who were native users of ASL, could achieve high inter-rater concordance, such as $86 \%$ on their overall assessment on the SCPI (Laird, 2005).

\section{Expert/Novice Paradigm}

In addition to looking at the relationship between fluency and cohesion, this study also looked at the performance of experts and novices. One benchmark 
to differentiate the two groups was national interpreter certification, cited by several researchers on ASL interpreters (Cokely, 1992; Davis, 2003; Russell, 2002). Those who had attained certification were thus deemed experts and those without were considered novices.

Years of second language study was the second benchmark used and this was also supported by a number of authors. Moser-Mercer (1997) postulated 5000 hours of study for expertise while in Dillinger's (1990) study, the experts had 3830 hours of professional experience. Ericsson (2000) suggested from 10 to 20 years to become "elite" (p. 213). In both Cokely (1992) and Russell's (2002) research, the experts had two decades if not more of language study and professional experience.

To operationally define the concept of novice, an individual was deemed such in this study if they had between five to seven years of language study. This was based on the literature on second language acquisition (Cummins, 2001) and the acquisition of ASL in particular (Jacobs, 1996). It was believed that five to seven years would lead to at least communicative competence in ASL. This range also reflected the amount of time needed to learn at least basic ASL and then complete an undergraduate degree in ASL interpreting at the time of this study.

Different cognitive abilities have been suggested in novices and experts, which may impact their fluency and their ability to create cohesive texts, both the focus of this study. For example, it has been suggested that novices spend more time working at the level of grammar (Liu, Schallert \& Carroll, 2004; Moser-Mercer, 2000). Novice ASL interpreters may not generalize inductively from past experiences, nor jump to inferences or take different perspectives (Taylor, 1990). This in turn makes it more difficult for them to determine significant meanings in a source text, versus trivial or irrelevant facts (Taylor, 1990). Part of this may be due to the lack of a welldeveloped schema for a number of disciplines, or the inability to rapidly access what they know of a speech event (Taylor, 1990).

On the other hand, experts were seen as those interpreters with enhanced metalinguistic abilities (Ehrensberger-Dow \& Perrin, 2009), which could potentially help create more cohesive texts. It was believed more facets of the interpreting process were automatic for them, which freed up their working memory for other tasks such as identifying patterns and selfmonitoring (Taylor, 1990, p. 38).

They could envision a broader sense of a speaker's meaning in context (Liu, Schallert \& Carroll, 2004; Moser-Mercer, 2000; Ronowicz \& Imanishi, 2003) and "perceive information in chunks," not as single units (Taylor, 1990, p. 39). They were seen as more adept at restructuring texts and identifying significant structures in a source message (Dillinger, 1990; Moser-Mercer, 1997), perhaps due to better developed "knowledge organization systems" (Taylor, 1990, p. 38). They were also seen as more proficient than novices at identifying both explicit and implied meanings (Liu, Schallert \& Carroll, 2004) and cause and effect relationships (Taylor, 1990).

Given the above characterizations of experts and novices from the literature, it was believed that the experts in this study might be more adept at cognitively identifying relationships within a text and then indicating them through the use of things like cohesive devices in their target texts. They might be more willing than a novice to restructure a target text to do so and not adhere to the form of the speaker's source message. In turn, it was thought the novices in this study would perform as those in Sunnari's (1995) research, who noted that the work of inexperienced interpreters could sound like a shopping list of topics that lacked cohesion. 


\section{Method}

A quantitative framework was followed in this study, where the performance of the interpreters was represented numerically, rank ordered and then compared. The goal was then to look for differences in cohesion between the target text of novices and expert interpreters when working from English into ASL. This study also looked at the relationship between perceived second-language fluency while interpreting and cohesion. Again, the fluency of each interpreter was represented numerically as a score and then rank ordered for comparison.

The non-parametric Mann-Whitney test was used instead of a parametric test to examine the interpreters' ranked scores for a number of reasons. This study included a small sample size (only 12 interpreters) and it looked at the abilities of two distinct groups (experts and novices) and not a representative sample of the field. Thus a normal distribution in the scores could not be assumed and parametric techniques were not deemed appropriate. Significance for the scores was reported for two-tailed tests, as it was believed a priori that either group could have had a higher or lower rank on the various areas studied.

\section{Source Text}

To begin the study, a story was created in spoken English (see Appendix A English Script). It contained vocabulary items taken out of typical textbooks used to teach beginning levels of ASL (Baker-Shenk \& Cokely, 1980;

Humphries, Padden \& O'Rourke, 1980; Valli \& Lucas, 1995) and the topics were thought to be familiar to the participants.

In the story, for example, the storyteller (the principal investigator of this study) described looking for employment as a teenager, finding a job with a Deaf individual and then taking ASL classes (Appendix A). As part of the story, he described events in an ASL course and finished by thanking the Deaf individuals who shared their language with him (Appendix A). The Deaf raters involved in this study had the opportunity to read over the transcript of the story (Appendix A) and watch the participants interpret the story and agreed that the topics should have been familiar to the novice and experts.

One of the participants, Alice-E, shared the following: "I felt like the story was a familiar one to me. In that, you know... everybody tells a story about their journey into the interpreting field. So I think I had a script for a schema for what was going to happen. And, ah, I always like the stories linked to one Deaf person who was significant in terms of acquiring language."

The story contained 783 words (where contractions such as "I'll" and "don't" were counted as two words) and was 7 minutes and 29 seconds in length. Including brief pauses at the end of each utterance, the speaking rate was approximately 104.4 words per minute. It was broken down into 100 utterances, each of which included one to two major independent propositions for the analysis process.

There were 23 instances of conjunctive devices (see Appendix A) that conjoined two independent sentences and these included discourse markers, coordinating conjunctions, conjunctive adverbs or adverbial phrases and prepositional phrases acting as discourse markers (see Fraser, 1999).

Conjunctive devices were counted if they linked two independent sentences together or if they signaled a linkage from one sentence to an earlier utterance. Thus they were acting across sentence boundaries, at the inter-sentential level as suggested by Halliday and Hasan (1976). Only discourse markers that occurred sentence initial were considered as those in sentence medial or final may have been acting as a subordinate conjunction within the sentence boundaries (intra-sentential). Where two conjunctions 
were used together such as "and so" or "so...but" (see Appendix A - English Script) they were counted as one instance.

\section{ASL Fluency Scale}

After the English story was created, a sign language proficiency rating scale was generated (see Appendix B - ASL Fluency Scale). It included six levels and was based on the descriptors used in other studies (California State University Northridge, 2007; Madsen, 2001; Newell \& Caccamise, 2007).

Twelve volunteers came forward and each was asked to first assess their fluency in ASL (Appendix B). They were then asked to listen to and simultaneously interpret the English source text while being videotaped. These target texts were transcribed into a written English gloss, where the interpreters' signs in ASL were transcribed into English words in capital letters, such as DEAF and HEARING for "Deaf" and "hearing."

These words represented the commonly understood citation form of signs in ASL as used in a number of texts (Baker-Shenk \& Cokely, 1980; Humphries, Padden \& O'Rourke, 1980). It should be noted, however, that the meaning of the English words used for the glosses as translation equivalents may not have captured all of the meanings inherent in the ASL signs. Also not captured in the basic glossing system used were several grammatical and paralinguistic features of the language, such as non-manual markers, intensity of signs, and the location of the signs in space.

A team of three Deaf native ASL signers then looked at each interpreter's target text and rated them on the ASL fluency form (Appendix B). One of these three raters also examined the written English glosses to ensure transcription accuracy. A high inter-rater agreement was reached with an average of $97.5 \%$ and a range from a low of $93 \%$ to a high of $99 \%$. As a form of member checking and to increase validity, the interpreters were then sent a copy of their simultaneous interpretation video along with the English gloss and asked to review both. In addition, they were given written feedback from the comments of the Deaf raters. Changes were made based on their feedback.

\section{Participants}

Two groups of interpreters participated in this study. Five individuals were nationally certified interpreters (the experts), and seven were recent graduates of an interpretation program (the novices). The participants did not have Deaf parents or Deaf family members, and had acquired ASL as an adult and as their second language, with English as their first. Two were male (both novices), and the remaining ten were female.

The certified interpreters ranged in age from mid forties to over 55 while the novices ranged from early twenties to two individuals in their late thirties. Each individual was given a pseudonym beginning with the first letter of the alphabet (Alice, Bea, Carol) and a final initial designating expert (-E) or novice (-N). Alice-E designates the first expert volunteer and Adam$\mathrm{N}$ the first novice.

The novices had studied ASL for between five to seven years and six of the seven had graduated from an ASL - English interpreter preparation program one month prior to this study. The seventh had graduated 13 months earlier. The five experts were all nationally certified and indicated having used ASL for more than twenty years. Such a range between the novices and experts was desirable, as it was believed this would better target differences between the groups. Ten described themselves as "White" or "Caucasian" and two individuals described themselves as Jewish.

Four of the certified interpreters had a Masters degree, while the fifth had completed a college diploma program. Only one of the expert interpreters had completed an interpreter preparation program. In addition to 
their three-year interpreter diploma, four of the novices held a Bachelor's degree, while three had taken some university level courses.

The three culturally Deaf native ASL signers were experienced ASL or interpreting instructors, in their late thirties and earlier forties and included a mix of men and women. All had been at a residential school for the Deaf and then later Gallaudet University for a number of years. Their degrees ranged from a Bachelor of Arts to a Master's.

\section{Analysis}

To begin the analysis, the individual ASL fluency scores were rank-ordered and compared between the interpreters using the Mann-Whitney nonparametric test. Next the fluency scores given to each interpreter by the three Deaf raters were also rank ordered and compared.

Next, the transcript of the English gloss for each interpreter's ASL target text was examined to see what his or her text looked like. The total number of signs produced was recorded as was the interpreter's unadjusted signs per minute, total number of unique signs and the number of propositions omitted. Also recorded was the total number of third person pronouns the interpreter used (pronouns, reflexive pronouns and possessive determiners or adjectives) that were manually produced. Not counted was their use of first or second person pronouns or indefinite pronouns as these were deemed not cohesive (Halliday \& Hasan, 1976). Also not recorded was non-manual means to indicate reference in ASL (use of space, eye-gaze, body leans, prosody, or the indication of reference through subject verb agreement). Taken together, these numbers represented a snapshot of the characteristics of each interpreter's work. They were then rank ordered for comparison.

Next the original source text in English and the glossed samples of target text translations were assessed for the number of cohesive ties due to conjunctive devices. Conjunctions included the list identified in the literature review and were considered cohesive if they acted across sentences and if they created a cohesive tie according to Halliday and Hasan's (1976) model. However, where they conjoined two nouns or verbs (compounding them) or a main clause and a subordinate clause, they were not included. The number of cohesive conjunctions were then totalled for comparison and rank ordered.

When it came to discourse markers, both the English source and the target ASL texts were examined and only those markers that occurred sentence initial and which functioned to tie sentences together were counted. Not included were discourse markers used by the interpreters in their ASL target texts such as OIC/OH-I-SEE, TRUE/REAL, or TRUE-BUSINESS as these were comments from the speaker about his or her own beliefs or internal cognitive processes (Fraser, 1999). Where the sign HEY served as an attention getting behavior or did not function cohesively it was also not counted.

\section{Study Limitations}

There were a number of limitations to this study that should be noted. To begin with, the interpreters worked from one direction, from English into ASL and with a monologic text. Different results may have been found with a dialogic text, or where the interpreters worked from ASL into spoken English, or with texts representing different registers.

The sample size was small, with only 12 participants. A broader range of interpreters and the inclusion of those with Deaf parents or Deaf family members may have resulted in different results. Only conjunctive devices, one aspect of cohesion according to Halliday and Hasan (1976), were explored. An examination of ellipsis, substitution, and lexical cohesion as 
well as a more in-depth look at reference may have provided different insight into why interpreters are deemed more or less fluent by native signers.

Finally, only three Deaf raters were employed in this study, all with a post-secondary degree and experience teaching hearing adults ASL or interpreting. Different Deaf assessors may have given the interpreters different ratings of fluency.

\section{Findings}

\section{Target Text Characteristics}

To compare the target texts of the experts and novices at a basic level and to see what characteristics differed, the number of signs, unique signs, and signs per minute were calculated for each. Also counted was their inclusion of third person endophoric reference produced manually and the number of propositions they omitted out of the original 100 in the source text. These were then rank ordered and compared using the Mann-Whitney nonparametric test at the 0.05 level of confidence.

No significant difference was found on the Mann-Whitney between the two groups $(\mathrm{N}=12, \mathrm{p}=0.57, \mathrm{Z}=-0.57$ ) in terms of the total number of signs they produced. When the total number of unique signs used by each interpreter was compared, again no significant difference was found $(\mathrm{N}=12$, $p=0.07, Z=-1.79$ ). Finally, the number of signs per minute, unadjusted for pauses, was calculated and then rank ordered. Again, no significant difference was found between the two groups $(\mathrm{N}=12, \mathrm{p}=0.57, \mathrm{Z}=-0.57)$.

Next, and as part of the analysis of the participants' target texts, the number of manual signs produced to indicate reference (third person pronouns, possessive pronouns, reflexive pronouns) were tallied and compared. Both groups produced fewer manual references than the number of tokens in the source text (59 English references); however, there was no significant difference between the experts and novices in this aspect $(N=12$, $\mathrm{p}=0.46, \mathrm{Z}=-0.74$ ).

As mentioned in the Methods section, the English source text (Appendix A) was broken down into 100 utterances. To further compare the target texts of the two groups the number of utterances each person omitted was computed. The expert group had slightly fewer omissions than the novice group but the difference was not significant $(\mathrm{N}=12, \mathrm{p}=0.361, \mathrm{Z}=$ 0.914).

\section{Fluency}

The next area addressed was that of fluency. The three Deaf raters jointly assessed each participant's ASL fluency on a six-point scale (Appendix B) and these score were then ranked. Using the Mann-Whitney non-parametric test, the ranked ASLPI ratings given by the Deaf raters were significantly higher for the experts than the novices at the 0.01 level $(\mathrm{N}=12$, **p $=0.006$, $\mathrm{Z}=-2.72$ ).

As a means of triangulation with the literature and findings of the Deaf raters, the individual interpreters were asked to assess their own fluency in ASL. There was a significant difference between the experts' and novices' self-assessments at the 0.05 level $\left(\mathrm{N}=12,{ }^{*} \mathrm{p}=0.01, \mathrm{Z}=-2.58\right)$, where the experts gave themselves a higher fluency rating.

\section{Conjunctions and Discourse Markers}

The final area of investigation, and the focus of this study, was conjunctive devices. Appendix C provides a list of all of the conjunctive devices in ASL used by each interpreter. The following are two examples of the conjunctive devices used by two novices and two experts in different sections of the English source text. 
In the first example and in the English source, there were two instances of cohesive conjunctions across clauses with the use of "and" as well as "and so." In the novice's text, Adam-N, we see the use of only one conjunction, AND, to conjoin ONE-ON-ONE (which was used to translate the English word "guide") and INTERPRET. According to Halliday and Hasan's (1976) model of cohesion, this would not be cohesive as it does not join two independent clauses. On the other hand and in the expert's text, Alice-E, we see the use of MEAN and PLUS to add cohesion between two independent clauses.

Source: Bill was born Deaf, and at the age of about 70, ah he was in pretty frail shape .... and so he needed a guide and an interpreter to get him around.

Table 1 Example of Adam-N and Alice-E's Target Texts

\begin{tabular}{|l|l|}
\hline & Target Text \\
\hline Adam-N & BILL HIMSELF BORN DEAF. \\
& GREW-UP, AGE, AGE 70, AGE 70. \\
& HE WOW HEALTH GO-DOWN. \\
& HE NEED GUIDE (to left), ONE-ON-ONE (in centre, move \\
& forward) AND INTERPRET (in centre) FOR HIM. \\
\hline Alice-E & HE BORN DEAF. \\
& HIMSELF AGE 70, HEALTH GO-DOWN++. \\
& MEAN ONE-ON-ONE (in circle), SOMEONE INTERPRET FOR \\
& HIM, PLUS GUIDE, WITH ONE-ON-ONE (in circle) FOR \\
& THEM/THERE. \\
\hline
\end{tabular}

In this next example, we compare the work of Elizabeth-N (a novice) to Carol-E (an expert). The English source message had one example of a cohesive conjunction, the word "but." Elizabeth-N's target text contained no conjunctive device. Carol-E's target text, on the other hand, had at least four conjunctive devices or discourse markers (SO/WELL, MEANS, WELL, INSTEAD).

Source: Now had my parents been Deaf, I would have known sign language from an early age. But... I learned ASL at the hands of a series of talented Deaf instructors, perhaps like many of you did.

Table 2 Example of Elizabeth-N and Carol-E's Target Texts

\begin{tabular}{|l|l|}
\hline & Target Text \\
\hline Elizabeth-N & MY PARENTS TWO-OF-THEM [on right] DEAF? \\
& NO NO. \\
& SUPPOSE PARENTS [gaze right and up] DEAF, GROW-UP \\
& (two handed) SIGN-ASL [gaze right]... ME [head nod "no"]. \\
& MY TEACHER [on left] [gaze left] TEACH-ME ASL. \\
& SAME-AS [from left to right] YOU MAYBE? \\
\hline Carol-E & SO/WELL, SUPPOSE PARENTS MINE DEAF, MEANS \\
& GROW-UP [role shift to left], ASL, RECEIVE-THRU-EYES \\
& [from right], SIGN-ASL, GROW-UP, SIGN-ASL. \\
& WELL, PARENTS DEAF NOT. \\
& [role shift right] INSTEAD LEARN HOW? THEY [on left] \\
& TEACHER [gaze left] TEACH-ME. \\
& THEY SKILLED [gaze left],THEY [on left] \\
& [role shift left] YOURSELVES (on right) INTERPRETER \\
& KNOW SAME-AS [teacher same-as you] MAYBE?
\end{tabular}

Some of the conjunctive devices used by the participants were not reported in the literature (such as INSTEAD used by Carol in the example above and by Denise in her target text), but these "non-typical" conjunctive 
devices were included as they conjoined two complete utterances or served as a discourse marker. Examples of these can be found in Appendix D Atypical Conjunctions. They were totaled and then ranked (Table 3), and the two groups were compared. While there were 23 conjunctive devices and discourse markers in the original source text (Appendix A), the target texts of the experts had a mean of 35 and a median of 35 while the texts created by the novices had a mean of 24.57 and a median of 26 .

Table 3 - Total Conjunctions

\begin{tabular}{|c|c|r|r|}
\hline Participant & Group & Total & Rank \\
\hline Alice- $E$ & 1 & 35 & 9.5 \\
\hline Bea- $E$ & 1 & 36 & 11 \\
\hline Carol- $E$ & 1 & 37 & 12 \\
\hline Denise- $E$ & 1 & 35 & 9.5 \\
\hline Erin- $E$ & 1 & 32 & 7 \\
\hline Adam- $N$ & 2 & 30 & 6 \\
\hline Barry- $N$ & 2 & 20 & 3 \\
\hline Christine- $N$ & 2 & 14 & 1 \\
\hline Darlene- $N$ & 2 & 34 & 8 \\
\hline Elizabeth- $N$ & 2 & 19 & 2 \\
\hline Francine- $N$ & 2 & 29 & 5 \\
\hline Gloria- $N$ & 2 & 26 & 4 \\
\hline
\end{tabular}

There was a significant difference at the 0.01 level between the number of conjunctive devices used by the novices when compared to the experts on the Mann-Whitney $\left(\mathrm{N}=12,{ }^{*} \mathrm{p}=0.007, \mathrm{Z}=-2.68\right)$, where the experts used more.

Next only the conjunctive devices used by the interpreters and mentioned in the literature (the typical conjunctions) were examined (Table 4). These included the ASL signs AND, ANYWAY, BUT, FINALLY/SUCCEED, FIND, FINISH, FOR-FOR, HAPPEN, HIT, KNOW/KNOW-THAT, MEAN, NOW, PLUS, SO/WELL, WHY, WRONG and UNDERSTAND.

Table 4 - Total Typical Conjunctions

\begin{tabular}{|l|c|r|r|}
\hline Participant & Group & \multicolumn{1}{|l|}{ Total } & \multicolumn{2}{|l|}{ Rank } \\
\hline Alice- $E$ & 1 & 29 & 8.5 \\
\hline Bea- $E$ & 1 & 32 & 11 \\
\hline Carol- $E$ & 1 & 33 & 12 \\
\hline Denise- $E$ & 1 & 25 & 7 \\
\hline Erin- $E$ & 1 & 30 & 10 \\
\hline Adam- $N$ & 2 & 22 & 5 \\
\hline Barry- $N$ & 2 & 18 & 3 \\
\hline Christine- $N$ & 2 & 10 & 1 \\
\hline Darlene- $N$ & 2 & 29 & 8.5 \\
\hline Elizabeth- $N$ & 2 & 13 & 2 \\
\hline Francine- $N$ & 2 & 22 & 5 \\
\hline Gloria- $N$ & 2 & 22 & 5 \\
\hline
\end{tabular}

When only the "typical" conjunctions were looked at the experts had a mean of 29.8 and median of 30 conjunctive devices while the novices had a mean of 19.43 and a median of 22. Again, a significant difference was found 
on the Mann-Whitney at the 0.01 level $\left(\mathrm{N}=12,{ }^{*} \mathrm{p}=0.009, \mathrm{Z}=-2.62\right)$, where the experts used more of the "typical" conjunctions than the novices.

A comparison was then done of the ranked ASL fluency scores given to each interpreter by the Deaf raters and their ranked, total use of conjunctive devices. A significant positive correlation was found using Spearman's rho between increased ASL fluency scores and the increased use of conjunctions $\left(\mathrm{r}=0.61,{ }^{*} \mathrm{p}=0.03\right)$. A scatterplot (Figure 1) graphically shows the correlation between the interpreters' rated fluency in ASL and their production of conjunctive devices, where those who used more conjunctive devices were rated as more fluent.

Figure 1 - ASL Fluency and Conjunctions

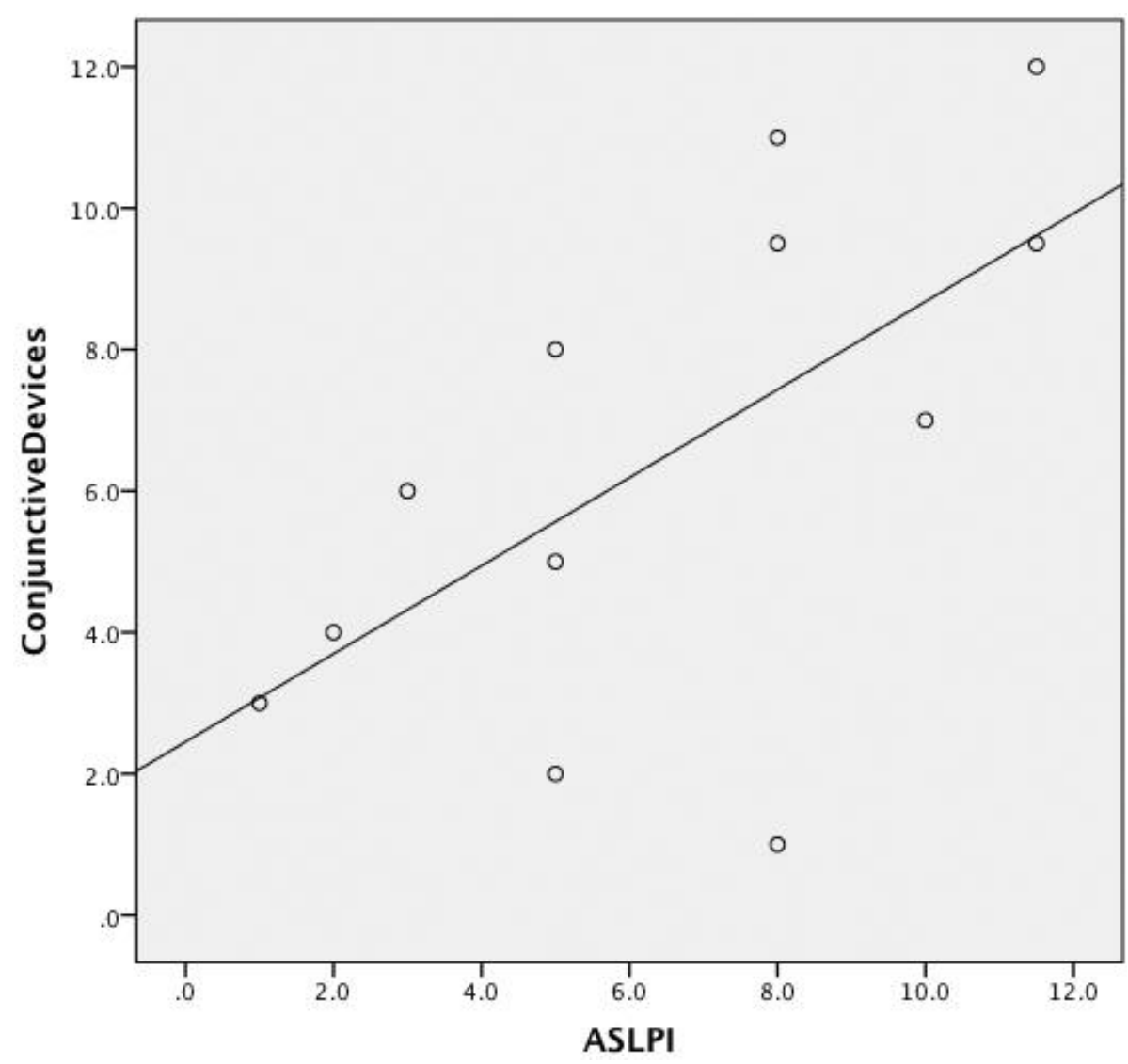

\section{Discussion}

\section{Novices or Experts}

Turning to the first research question, "What differences in cohesion can be found in the target texts of novice and expert interpreters working simultaneously from their A language (English) into their B language (ASL)?" the findings of this study indicate a significant difference in terms of the addition of conjunctive devices including discourse markers by the experts $(* * p=0.007)$. The assessment of conjunctive devices might be a means, therefore, of ascertaining increased competency while interpreting.

\section{ASL fluency}

In terms of the second research question, "What is the relationship between perceived fluency in ASL and the use of cohesive devices in the ASL target texts of sign language interpreters?" the results of this study indicated that conjunctive devices might play an important role. To begin with, the experts were deemed by the Deaf raters as significantly more fluent than the novices 
based on their ASL target texts while interpreting $(* * p=0.006)$. As mentioned earlier, they also included significantly more conjunctive devices than the novices in their ASL target texts.

Looking at other characteristics of the interpreters' target texts, however, revealed no other significant difference. For example, there was no difference in the amount of sign vocabulary they used in their target texts ( $\mathrm{p}$ $=0.57)$, in the unique number of signs they produced $(p=0.07)$, or their use of overt manual third person reference marking with ASL pronouns $(\mathrm{p}=$ $0.46)$. There was also no significant difference in terms of their signs per minute $(\mathrm{p}=0.57)$ or in the amount of information they omitted while interpreting $(p=0.361)$. Perhaps for this group of Deaf raters, the use of conjunctive devices signalled greater levels of fluency in ASL.

\section{Interpretation Process}

The findings of this study shed some light on the process of simultaneously interpreting. For example, there is support for the philosophy of Blum-Kulka (2000) and Seleskovitch and Lederer (1995) that some aspects of cohesion must be added to target texts at times, perhaps to create coherence. For example, in comparison to the source text, where there were 23 conjunctive devices, nine of the twelve interpreters included more cohesive devices in their ASL target texts.

Only three of the interpreters, all novices, produced fewer overt conjunctive devices in their target text than the source (Barry-N, Christine$\mathrm{N}$, Elizabeth-N). Given that the experts were deemed more fluent (**p $=$ 0.006) and produced significantly more conjunctive devices than the novices $(* * p=0.007)$, and given the positive correlation between increased fluency and increased use of conjunctive devices $(r=0.61, * p=0.03)$, this supports the prediction that more experienced interpreters add conjunctive devices to their target texts.

\section{Accuracy}

The next area that this study sheds some light on is the importance of cohesion in the accuracy of target texts. Returning to the first of the two examples provided in the Findings section, the storyteller said the following:

Bill was born Deaf, and at the age of about 70, ah he was in pretty frail shape ... and so he needed a guide and an interpreter to get him around.

Table 5 Adam- $\mathrm{N}$ and Alice-E Accuracy

\begin{tabular}{|c|c|c|}
\hline & Target Text & $\begin{array}{l}\text { Possible Back } \\
\text { Translation }\end{array}$ \\
\hline Adam-N & $\begin{array}{l}\text { BILL HIMSELF BORN DEAF. } \\
\text { GREW-UP, AGE, AGE 70, AGE } 70 . \\
\text { HE WOW HEALTH GO-DOWN. } \\
\text { HE NEED GUIDE (to left), ONE-ON- } \\
\text { ONE (moves forward) AND } \\
\text { INTERPRET (in centre) FOR } \\
\text { HIM. }\end{array}$ & $\begin{array}{l}\text { Bill was born Deaf. } \\
\text { He had grown-up and } \\
\text { was } 70,70 \text { years old. } \\
\text { He had become very } \\
\text { unwell. } \\
\text { He needed a guide and } \\
\text { also another person, an } \\
\text { interpreter. }\end{array}$ \\
\hline Alice-E & $\begin{array}{l}\text { HE BORN DEAF. } \\
\text { HIMSELF AGE 70, HEALTH GO- } \\
\text { DOWN++ MEAN ONE-ON-ONE } \\
\text { (in circle), SOMEONE } \\
\text { INTERPRET FOR HIM, PLUS } \\
\text { GUIDE, WITH ONE-ON-ONE (in } \\
\text { circle) FOR THEM/THERE. }\end{array}$ & $\begin{array}{l}\text { He was born Deaf. } \\
\text { When he was } 70 \text {, he } \\
\text { became very unwell } \\
\text { which meant he needed } \\
\text { someone to work with } \\
\text { him to interpret for him. } \\
\text { Also he needed a guide } \\
\text { to get him around } \\
\text { there/them. }\end{array}$ \\
\hline
\end{tabular}


Adam-N and Alice-E's interpretations and a possible back translation of each are included below. We see in Alice-E's interpretation that the reason for Bill needing an interpreter was clearly due to his age and frailty, which was implied but not overtly stated in Adam-N's interpretation. It would thus be left up to a Deaf audience member to infer that connection.

Below is the second example included in the Findings section with the target texts for Elizabeth-N and Carol-E for the following source text utterance:

Now had my parents been Deaf, I would have known sign language from an early age. But... I learned ASL at the hands of a series of talented Deaf instructors, perhaps like many of you did.

In her target text, Carol-E makes it clear that because the speaker's parents were not Deaf, he had to learn ASL formally and from instructors. While Elizabeth-N does state that the speaker's parents were not Deaf, this occurred prior to the conditional "had they been Deaf" as a statement. The fact that the speaker did not learn ASL from his parents was not clearly stated but would have to be inferred by the audience.

The use of a cleft MY PARENTS TWO-OF-THEM DEAF, NO implies that something else was about to be said (someone else was Deaf, the parents were hearing), but instead the target text goes on to the conditional "if my parents were Deaf..." Also the use of two hands for the sign GROW-UP in neutral space seems to imply that it was the parents who grew up without ASL (which would make sense in context as they were not Deaf) but not that the speaker had grown up without the language.

Table 6 Elizabeth-N and Carol-E Accuracy

\begin{tabular}{|c|c|c|}
\hline & Target Text & $\begin{array}{l}\text { Possible Back } \\
\text { Translation }\end{array}$ \\
\hline $\begin{array}{l}\text { Elizabeth- } \\
N\end{array}$ & $\begin{array}{l}\text { MY PARENTS TWO-OF-THEM } \\
\text { [on right] DEAF? } \\
\text { NO NO. } \\
\text { SUPPOSE PARENTS [gaze right } \\
\text { and up] DEAF, GROW-UP } \\
\text { (two-handed) SIGN-ASL [gaze } \\
\text { right]...ME [head nod "no"]. } \\
\text { MY TEACHER [on left] [gaze left] } \\
\text { TEACH-ME ASL. } \\
\text { SAME-AS [from left to right] YOU } \\
\text { MAYBE? }\end{array}$ & $\begin{array}{l}\text { It wasn't my parents who } \\
\text { were Deaf. } \\
\text { If they were Deaf, and } \\
\text { grew up signing ASL.... } \\
\text { I [didn't/not]. } \\
\text { My teacher taught me } \\
\text { ASL, like you maybe. }\end{array}$ \\
\hline Carol-E & $\begin{array}{l}\text { SO/WELL, SUPPOSE PARENTS } \\
\text { MINE DEAF, MEANS GROW- } \\
\text { UP [role shift to left], ASL, } \\
\text { RECEIVE-THRU-EYES [from } \\
\text { right], SIGN-ASL, GROW-UP, } \\
\text { SIGN-ASL. } \\
\text { WELL, PARENTS DEAF NOT. } \\
\text { [role shift right] INSTEAD LEARN } \\
\text { HOW? THEY [on left] } \\
\text { TEACHER [gaze left] TEACH- } \\
\text { ME. } \\
\text { THEY SKILLED [gaze left],THEY } \\
\text { [On left] [role shift left] } \\
\text { YOURSELVES (on right) } \\
\text { INTERPRETER KNOW SAME- } \\
\text { AS [teacher same-as you] } \\
\text { MAYBE? }\end{array}$ & $\begin{array}{l}\text { Well, if my parents had of } \\
\text { been Deaf, it meant I } \\
\text { would have grown up } \\
\text { seeing and signing ASL. } \\
\text { But, my parents were not } \\
\text { Deaf. } \\
\text { Instead, it was through } \\
\text { teachers that I learned } \\
\text { ASL. } \\
\text { They were very talented } \\
\text { instructors. } \\
\text { You as an interpreter } \\
\text { perhaps have had the } \\
\text { same experience? }\end{array}$ \\
\hline
\end{tabular}


In both cases, the novices' target tests are less cohesive than those of the experts and sound like a list of facts. This supports the observation of Sunnari (1995), that novices' target texts sounded disconnected and list-like unlike those of experts, perhaps due to the limited number of conjunctive devices used by the novices.

\section{Cognition}

The final contribution of this study is that it lends support for different cognitive processes or levels of focus between experts and novices. As reported in the literature, authors believed novices concentrated on surface structure features of a source text, such as grammar and vocabulary (Liu, Schallert \& Carroll, 2004; Moser-Mercer, 2000). In turn, they seemed to fail at considering the function of a text or its meaning in context and so do not demonstrate meta-linguistic abilities, as experts were expected to do (Ehrensberger-Dow \& Perrin, 2009; Liu, Schallert \& Carroll, 2004; MoserMercer, 2000; Ronowicz \& Imanishi, 2003).

The significant lack of additional conjunctive devices in the novices' target texts as compared to the experts $(* * \mathrm{p}=0.007)$ suggest the experts went beyond the surface level or at least the sentence level in their creation of an ASL target, to try and show what they believed to be the relationships between the sentences or paragraphs. The novices, on the other hand, seemed to represent in their ASL target texts a similar number of conjunctive devices as found in the English source. 


\section{References}

Bailey, C. S. \& Dolby, K. (2002). The Canadian Dictionary of ASL. Edmonton, Alberta: The University of Alberta Press.

Baker, M. (1992) In Other Words: A Coursebook on Translation. New York: Routledge.

Baker-Shenk, C. \& Cokely, D. (1980). American Sign Language: A teacher's resource text on grammar and culture. Washington, DC: Clerc Books, Gallaudet University Press.

Becher, V. (2011). Whey and why do translators add connectives? A corpus based study. Target, 23(1), 26-47 DOI: 10.1075/target.23.1.02bec

Blum-Kulka, S. (2000). Shifts of cohesion and coherence in translation. In L. Venuti (Ed.), The Translation Studies Reader (pp. 298-313). London and New York: Routledge.

Burch, D. D. (1997). Relationship of the Sign Language Proficiency Interview and the National Association of the Deaf Interpreter Assessment Program in the Louisiana State Certification of sign language interpreters. In M. L. McIntire \& S. Wilcox (Eds.), Journal of Interpretation (39-48). Silver Spring, MD: RID Publications.

California State University, Northridge. (2007). The American Sign Language Proficiency Interview - ASLPI. Retrieved December 1, 2008 from http://www.csun.edu/deafed/pdf/ASLPI\%20Description.pdf

Cerney, B. (2000). The ten C's of effective target texts. In D. Watson (Ed.), Journal of Interpretation (pp. 131-150). Silver Spring, MD: RID Publications.

Cokely, D. (1992). Interpretation: a sociolinguistic model. Burtonsville, Maryland: Linstok Press.

Conlin, F., Hagstrom, P. \& Neidle, C. (2003). A particle of indefiniteness in American Sign Language. Linguistic Discovery, 2(1). Retrieved July 9 2013 from http://journals.dartmouth.edu/cgibin/WebObjects/Journals.woa/1/xmlpage/1/archive

Coppock, P. J. (1992). Interpreting discourse - signs for the future? In J. Plant-Moeller (Ed.), Expanding Horizons: Proceedings of the Twelfth National Convention of the Registry of Interpreters for the Deaf (pp. 37-58). Silver Spring, MD: RID Publications.

Cummins, J. (2001). Negotiating Identities: Education for Empowerment in a Diverse Society. Second Edition. Los Angeles, California: California Association for Bilingual Education.

Davidson, K., Caponigro, I., \& Mayberry, R. (2009). Testing calculation of scalar implicatures in English and American Sign Language. In C. Cecchetto (Ed.), Proceedings of the Workshop on Formal Approaches to Sign Languages at the Twenty-First ESSLLI (pp. 1-12). Retrieved July 6 2011 from

http://esslli2009.labri.fr/documents/05_Davidson_Caponigro_Mayberry _ESSLL_2009.pdf

Davis, J. E. (2003). Cross-linguistic strategies used by interpreters. Journal of Interpretation. Alexandria, Virginia: Registry of Interpreters for the Deaf, Incorporated.

Desrosiers, G. (2001). Where is the national certification for education interpreters? The AVLIC News, 16(4) (Winter), 1 - 3.

Dillinger, M. (1990). What do interpreters know that bilinguals don't? The Interpreters' Newsletter [Trieste, Italy], 3, 41-58.

Ehrensberger-Dow, M., \& Perrin, D. (2009). Capturing translation processes to access metalinguistic awareness. Across Languages and Cultures, 10(2), 275-288. DOI: 10.1556/Acr.10.2009.2.6

Ericsson, K. A. (2000). Expertise in interpreting: An expert-performance perspective. Interpreting, 5(2), 187-220.

Fasold, R., \& Connor-Linton, J. (2006). An Introduction to Language and 
Linguistics. New York: Cambridge University Press.

Fischer, S., \& Lillo-Martin, D. (1990). Understanding conjunctions. International Journal of Sign Linguistics, 1(2), 71-80.

Fraser, B. (1999). What are discourse markers? Journal of Pragmatics, 31, 931-952

Gumul, E. (2006). Explicitation in simultaneous interpreting: A strategy or a by-product of language mediation? Across Languages and Cultures, 7(2), 171-190. DOI: 10.1556/Acr.7.2006.2.2

Halliday, M. A. K., \& Hasan, R. (1976). Cohesion in English. London: Longman.

Hoza, J. (2011). Discourse and politeness functions of HEY and WELL in American Sign Language. In C. B. Roy (Ed.), Discourse in Signed Languages (pp. 69-95). Washington, DC: Gallaudet University Press. Accessed July 7, 2013 from http://gupress.gallaudet.edu/excerpts/DISL.html

Humphries, T., Padden, C., \& O'Rourke, T. J. (1980). A Basic Course in American Sign Language: Student Study Guide. Silver Spring, MD: TJ Publishers, Inc.

Humphries, T., Padden, C., \& O'Rourke, T. J. (1986). A Basic Course in American Sign Language. Silver Spring, MD: TJ Publishers, Inc.

Jacobs, R. (1996). Just how hard is it to learn ASL? The case for ASL as a truly foreign language. In C. Lucas (Ed.), Multicultural Aspects of Sociolinguistics in Deaf Communities (pp. 183-226). Washington, D.C.: Gallaudet University Press.

Janzen, T. (2007). The expression of grammatical categories in signed languages. In E. Pizzuto, P. Pietrandrea and R. Simone (Eds.), Verbal and Signed Languages: Comparing Structures, Constructs and Methodologies (pp. 171- 198). Berlin, Germany: Mouton de Gruyter.

Jones, L. K. (1992) In pursuit of discourse particles. In S. J. J. Hwang and W. R. Merrifield (Eds.) Language in Context: Essays for Robert E Longacre (pp. 127-136). (A Publication of the Summer Institute of Linguistics and the University of Texas at Arlington). Retrieved July 6 2013 from http://www-01.sil.org/acpub/repository/31853.pdf

Jucker, A. H. (1993). The discourse maker well: A relevance-theoretical account. Journal of Pragmatics, 19, 435-452

Kelly, J. E. (2004). ASL-to-English Interpretation: "Say it like they mean it." Alexandria, VA: RID Press

La Bue, M. A. (1998). Interpreted education: A study of deaf students' access to the content and form of literacy instruction in a mainstreamed high school English class. Retrieved from ProQuest Dissertations and Theses. (No. 9830061)

Laird, E. (2005) American Sign Language proficiency: A study of agreement among raters. Retrieved from Proquest Dissertations \& Theses. (No. AAT 3212188).

Langer, E. C. (2007). Classroom discourse and interpreted education: What is conveyed to Deaf elementary school students. (Doctoral Dissertation). Retrieved from ProQuest Dissertations and Theses. (No. 3256442).

Larson, M. L. (1998). Meaning-Based Translation (Second Edition). Lanham, MD: University Press of America, Inc.

Liu, M., Schallert, D. L., \& Carroll, P. J. (2004). Working memory and expertise in simultaneous interpreting. Interpreting 6(1), 19-42.

Madsen, W. J. (2001). Sign Language Proficiency Testing at Gallaudet University: Notes to Prospective SCPI Examinees. Accessed December 1, 2008 from http://gspp.gallaudet.edu/ncate/pdf/.\%5Cstandard2\%5CAppen3scpiexa mnotes.pdf

Matei, M. (2010). Discourse markers as functional elements. Bulletin of the Transilvania University of Brasov, 3(52), 119 - 126. 
Mey, J. L. (2001) Pragmatics: An Introduction (Second Edition). Malden, MA: Blackwell Publishing.

Morford, J. P., \& MacFarlane, J. (2003). Frequency characteristics of American Sign Language. Sign Language Studies, 3(2), 213-225.

Moser-Mercer, B. (1997). The expert-novice paradigm in interpreting research. In E. Fleischmann, W. Kutz and P. A. Schmitt (Eds.), Translationsdidaktik. Grundfragen der Übersetzungswissenschaft (pp. 255-261). Tübingen: Gunter Narr.

Moser-Mercer, B. (2000). Simultaneous interpreting: Cognitive potential and limitations. Interpreting, 5(2), 83-94

Napier, J. (2005). Linguistic features and strategies of interpreting: from research to education to practice. In M. Marschark, R. Peterson \& E. A. Winston (Eds.), Sign Language Interpreting and Interpreter Education: Directions for Research and Practice (pp. 84-111). New York: Oxford University Press.

Newell, W., \& Caccamise, F. (2007). Section 10: Connecting American Sign Language (ASL) Instruction and the Sign Language Proficiency Interview (SLPI). Rochester, NY: National Technical School for the Deaf. Accessed July 5, 2008 from www.rit.edu/ntid/slpi

Quigley, S. P., \& Paul, P. V. (1984). Language and Deafness. San Diego, California: College-Hill Press.

Robinson, D. (1997). What is Translation? Centrifugal Theories: Critical Interventions. Kent, Ohio: Kent State University Press.

Ronowicz, E. \& Imanishi, K. (2003). A comparison of task management and lexical search mechanisms in novice and professional translators/interpreters. Interpretation Studies, 3, 16-24. Retrieved January 122012 from http://wwwsoc.nii.ac.jp/jais/kaishi2003/pdf/02ronowicz_final_.pdf

Roy, C. B. (1987). Evaluating performance: An interpreted lecture. In M. L. McIntire (Ed.), New Dimensions in Interpreter Education: Curriculum and Instruction (pp. 139-147). United States: Conference of Interpreter Trainers.

Roy, C. (1995). Features of discourse in an American Sign Language lecture. In C. Valli \& C. Lucas (Eds.), Linguistics of American Sign Language: An Introduction (pp.394-408). Washington, DC: Gallaudet University Press.

Rudser, S. F. (1986). Linguistic analysis of historical change in interpreting: 1973 - 1985. In M. McIntire (Ed.), Interpreting: the art of cross-cultural mediation (pp. 123 - 127). Silver Spring, MD: RID Publications.

Russell, D. (2002). Reconstructing our views: Are we integrating consecutive interpreting into our teaching and practice. In L. Swabey (Ed.), New Designs in Interpreter Education: Proceedings of the 14th National Convention Conference of Interpreter Trainers (pp. 5-15). United States: Conference of Interpreter Trainers.

Russell, D., \& Malcolm, K. (1992). Interpreting in Canada. In J. PlanMoeller (Ed.), Expanding Horizons: Proceedings of the Twelfth National Convention of the Registry of Interpreters for the Deaf (pp. 23 - 36). Silver Spring, MD: RID Publications.

Scheetz, N. A. (2009). Building ASL Interpreting and Translation Skills: Narratives for Practice. New York: Pearson Education, Inc.

Schiffrin, D. (1987). Discourse Markers. New York: Cambridge University Press

Seleskovitch, D., \& Lederer, M. (1995). A systematic approach to teaching interpretation (J. Harmer, Trans.). Silver Spring, Maryland: The Registry of Interpreters for the Deaf. (Original work published 1989).

Shlesinger, M. (1995). Shifts in cohesion in simultaneous interpreting. The Translator, 1(2), 193-214

Shlesinger, M., \& Ordan, N. (2012). More spoken or more translated? 
Exploring a known unknown of simultaneous interpreting. Target, 24(1), 43-60. DOI: 10.1075/target.24.1.04shl

Siple, L. (1995). The use of addition in sign language transliteration.

Unpublished doctoral dissertation. University of New York Buffalo.

UMI Number 9617912

Sunnari, M. (1995). Processing strategies in simultaneous interpreting: Experts vs. novices. In P. W. Krawutschke (Ed.) Proceedings of the 36th Annual Conference of the American Translators Association (pp. 157164). Medford, NJ: Information Today, Inc.

Taylor, M. (1990). The novice, competent or expert interpreter: what are you? In Sara MacFayden (Ed.), Gateway to the Future. Papers from the 1990 AVLIC Conference (pp. 37 - 46). Edmonton, Alberta: Association of Visual Language Interpreters of Canada.

Valli, C., \& Lucas, C. (1995). Linguistics of American Sign Language: An Introduction (Second Edition). Washington, D.C.: Gallaudet University Press.

Wilbur, R. B. (1994). Foregrounding structures in American Sign Language. Journal of Pragmatics, 22, 647-672.

Winston, E. (1992). Space and involvement in an American Sign Language lecture. In J. Plant-Moeller (Ed.), Expanding Horizons: Proceedings of the Twelfth National Convention of the Registry of Interpreters for the Deaf (pp. 93-105). Silver Spring, MD: Registry of Interpreters for the Deaf.

Winston, E., \& Monikowski, C. (2003). Marking topic boundaries in signed interpretation and transliteration. In M. Metzger, S. Collins, V. Dively \& R. Shaw (Eds.), From Topic Boundaries to Omissions: New Research on Interpretation (pp. 187-237).Washington, DC: Gallaudet University Press.

Zimmer, J. (1992). Appropriateness and naturalness in ASL/English interpreting. In J. Plant-Moeller (Ed.), Expanding Horizons: Proceedings of the Twelfth National Convention of the Registry of Interpreters for the Deaf (pp. 81-92). Silver Spring, MD: RID Publications. 


\section{Appendix A - English Script}

Words in bold represent conjunctive devices.

Hello. My name is Bob ... and I want to tell you about my journey learning American Sign Language as a teenager, and how I got into interpreting.

Now had my parents been Deaf, I would have known sign language from an early age.

But... I learned ASL at the hands of a series of talented Deaf instructors, perhaps like many of you did.

Anyway, l've jumped way far ahead....ah, let me go back and tell you why I learned ASL.

Ah, perhaps like many high school students, I really wanted to spend my teenage years watching a lot of TV.

But, unlike some of the better off students in high school, I was in desperate need of money to keep my car on the road and to pay for clothes and for my phone plan.

So guess what?

I had to find a part-time job.

So... after a long hard look through the local ads, I found an opening, working as an aide for Deaf Support Services with one Deaf senior, ah, who l'll call Bill.

Bill was born Deaf, and at the age of about 70 , ah he was in pretty frail shape ... and so he needed a guide and an interpreter to get him around.

I should tell you at that time that I applied, I had learned the alphabet from a friend of mine who had learned it in the Girl Scouts.

That was about all I knew.

She taught it to a few of us so we could talk in class without the teachers knowing.

We did get caught a few times, so... but the teachers weren't savvy enough to understand what we were doing.

They just knew we weren't paying attention.

Anyway, Deaf Support Services called me in for an interview, and that was when I met and starting working with Bill.

Looking back now, I am pretty sure it was my interest in fishing that got me hired, and not my ASL fluency.

According to Bill, I was the only one who mentioned liking outdoor activities, so he suspected he might finally get back to using his beloved rod and reel.

Once a fisherman, always a fisherman, I guess.

I worked with Bill for about 2 years... and took ASL classes for free, thanks to Deaf Support Services.

During that time, Bill was the only Deaf person I spent time with aside from my ASL instructors.

I also didn't have all the resources folks do now to learn ASL either.

I relied pretty heavily on my ASL tape, with a handful of ASL stories.

There were also very few interpreters around that I could talk... that I could look to for role models or advice.

But regardless of that, my language level of fluency changed pretty quickly in those 2 years.

I guess a good student is a good student after all.

Some funny things happened, well I thought they were funny.

I remember taking my fourth ASL class.

The night before a test, I was running around my house trying to find my ASL tape or my ASL dictionary, to practice, before a receptive finger-spelling test.

When I realized both were gone, I immediately suspected my sister and was ready to kill her.

But it wasn't my sister who had touched them.

When I finally found my tape in the VCR and started watching it, I realized that I was at fault for having left it in the machine, and I had recorded my favorite science fiction movie over the entire thing! 
I also remembered that what I had left back in my locker at the school was my dictionary.

So much for practicing.

I tried to explain to my ASL instructor what had happened, but after about 5 minutes I gave up and I just signed, "My dog ate my tape".

She didn't see the humor in it!

She also said in all her experience, I was the only student to lose both my ASL videotape and my ASL dictionary.

She then asked me where I was at the Deaf rally for ASL rights at the government building, the past weekend!

I agreed - that what I really needed was to spend more time with Deaf people outside of class.

Anything else just doesn't cut it.

Needless to say I lost my A+ average in that test, the fourth and final one for the class!

Looking back I have to thank my Deaf instructors for their support and teaching.

Oh, Bill by the way lived to the age of 78 .

I will never forget him, as he was really the reason that I got into interpreting. 
Appendix B - ASL Fluency Scale

\begin{tabular}{|c|c|}
\hline Rating & Descriptors \\
\hline 1 & $\begin{array}{l}\text { I know a few signs; it is hard to understand a Deaf person even when they are } \\
\text { signing slowly using simple language; there are very few topics I can talk about with } \\
\text { a Deaf person in ASL. }\end{array}$ \\
\hline 2 & $\begin{array}{l}\text { If I am very familiar with the topic, I can ask and answer questions in ASL. I can } \\
\text { understand simple questions and statements, especially if the person is signing } \\
\text { slowly, repeats her or himself, and paraphrases their signing for me. I can answer } \\
\text { basic questions about directions for traveling in a polite manner. I can talk about my } \\
\text { basic needs in ASL but not much more. I think I make many errors in production } \\
\text { and grammar but Deaf people - like my ASL teacher or my closest Deaf friends or } \\
\text { family members - can understand me. I believe my vocabulary and grammar are } \\
\text { limited. }\end{array}$ \\
\hline 3 & $\begin{array}{l}\text { I feel that my signing is good enough that I can communicate clearly in routine } \\
\text { social situations or in specific work-related settings. While I feel confident in signing } \\
\text { in most social situations, I know I am not the best signer. But I can make } \\
\text { introductions and casual conversation about current events. I can talk about work, } \\
\text { family, and my personal background in ASL. At work, I can talk to other Deaf } \\
\text { employees about specific job-related tasks, but I am not comfortable discussing } \\
\text { complex topics in ASL. I can get the gist of what a Deaf person is signing and they } \\
\text { seem to be able to understand me. I have enough vocabulary and knowledge of } \\
\text { ASL grammar to express everyday concepts without having to repeat or rephrase } \\
\text { frequently. I am not an expert in the grammar of ASL however. }\end{array}$ \\
\hline 4 & $\begin{array}{l}\text { I believe my ASL is good enough for me to participate in both formal and informal } \\
\text { conversations on typical every day work, social, and professional topics. I have a } \\
\text { broad enough vocabulary in ASL that I don't have to grope or think about the } \\
\text { correct sign to use very frequently. I can sign at a normal rate and I can understand } \\
\text { a conversation when the Deaf person signs at a normal rate. I don't make that } \\
\text { many errors or when I do make some, they do not interfere with the other person } \\
\text { understanding me. I can go into some detail about a topic in ASL. I still sign like a } \\
\text { hearing person, and have never been mistaken for a native signer or child of Deaf } \\
\text { parents. }\end{array}$ \\
\hline 5 & $\begin{array}{l}\text { I can understand and participate in conversations of a broad nature, and can } \\
\text { respond to questions or a discussion of a topic that is unfamiliar to me. I feel that I } \\
\text { have a high degree of fluency and an extensive vocabulary in ASL. I believe I make } \\
\text { few errors in sign production and grammar. I can tell when a Deaf person does not } \\
\text { understand what I am signing and can rephrase or adjust what I am saying to } \\
\text { clarify. I understand how to interrupt in ASL, how to start a conversation, and how to } \\
\text { maintain turn-taking. On one or two occasions a Deaf person has asked me if I was } \\
\text { a native signer or child of Deaf parents. }\end{array}$ \\
\hline 6 & $\begin{array}{l}\text { I believe then I am completely fluent in ASL and accepted by Deaf people and } \\
\text { native signers as a native signer myself. I have an extensive vocabulary and } \\
\text { knowledge of ASL idioms and colloquialisms. When I communicate in ASL with a } \\
\text { Deaf person, I feel confident that I am using polite language forms that are } \\
\text { appropriate for their culture. I can understand just about any topic of conversation in } \\
\text { ASL and a variety of signing styles. I can communicate in formal and informal ASL. I } \\
\text { have been asked, or can pass, as a native signer of ASL. }\end{array}$ \\
\hline
\end{tabular}


Appendix C - Conjunctive Devices

\begin{tabular}{|c|c|c|c|c|c|c|c|c|c|c|c|c|}
\hline Participant & 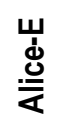 & 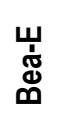 & 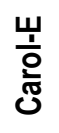 & 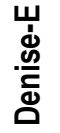 & 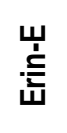 &  & 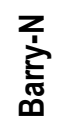 & 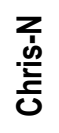 & 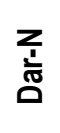 & 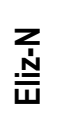 & 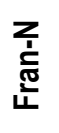 & 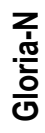 \\
\hline $\begin{array}{l}\text { Expert (1) } \\
\text { Novice (2) }\end{array}$ & 1 & 1 & 1 & 1 & 1 & 2 & 2 & 2 & 2 & 2 & 2 & 2 \\
\hline ADD & & 1 & & & & & & & & & & \\
\hline ALSO & 3 & & 1 & 5 & 1 & & 2 & 1 & 4 & 6 & 4 & 4 \\
\hline AND & & & & & & 1 & 1 & & & & & \\
\hline $\begin{array}{l}\text { ANYWAY } \\
\text { DOESN'T- } \\
\text { MATTER }\end{array}$ & 3 & 1 & 4 & 4 & 2 & 3 & 2 & & 2 & 2 & 2 & 2 \\
\hline BUT & 3 & & 4 & 4 & 6 & 1 & & & 6 & & 2 & 7 \\
\hline DURING & 2 & & & 1 & & & & & & & & \\
\hline $\begin{array}{l}\text { EVENTUALLY } \\
\text { TIME-PASSES }\end{array}$ & & 1 & & & & 1 & & & & & & \\
\hline EXAMPLE & & & & 1 & & & & & & & & \\
\hline $\begin{array}{l}\text { FINALLY } \\
\text { SUCCEED }\end{array}$ & 3 & & & & & 1 & 1 & & 1 & & 2 & 1 \\
\hline FIND & & & & & 2 & & & & & & & \\
\hline FINISH & & 1 & & & & 2 & & 1 & & & & \\
\hline FOR-FOR & & & 2 & & 1 & & & & & & & 1 \\
\hline $\begin{array}{l}\text { FROM-THEN- } \\
\text { ON }\end{array}$ & & & 1 & & 1 & 1 & & & & & & \\
\hline HAPPEN & & 4 & 4 & & 3 & 3 & & 1 & 1 & 3 & 1 & 2 \\
\hline HIT & & & & & & 1 & & 1 & 1 & & & \\
\hline INSTEAD & & & 1 & 2 & & & & & & & & \\
\hline $\begin{array}{l}\text { KNOW } \\
\text { KNOW-THAT }\end{array}$ & & 6 & 1 & 2 & 1 & 1 & & & & & & \\
\hline LATER & & & & 1 & & & & & & & & \\
\hline MEAN & 7 & 6 & 3 & 8 & 1 & & 1 & & 7 & & & 3 \\
\hline NOW & & 2 & & 4 & 1 & 2 & 1 & & & 2 & 3 & 1 \\
\hline NEXT & & & & & & 2 & & & & & & \\
\hline \multicolumn{13}{|l|}{ OPPOSITE } \\
\hline PLUS & 2 & 1 & & & 4 & 1 & & & & & & \\
\hline $\begin{array}{l}\text { POINT } \\
\text { OFF-POINT } \\
\text { BACK-TO- } \\
\text { POINT }\end{array}$ & & & & & & 3 & & 1 & & & 1 & \\
\hline $\begin{array}{l}\text { PUSH-LEFT } \\
\text { PUSH-RIGHT }\end{array}$ & & 2 & & & & & & 2 & & & 1 & \\
\hline SAME-TIME & 1 & & 1 & & & & & & & & 1 & \\
\hline $\begin{array}{l}\text { SO } \\
\text { WELL }\end{array}$ & 5 & 3 & 9 & 1 & 4 & 4 & 2 & 1 & 8 & 2 & 6 & 3 \\
\hline THEN & & & & & & 1 & & & 1 & & & \\
\hline WHY & 5 & 8 & 3 & & 1 & 1 & 6 & 3 & 3 & 2 & 4 & 2 \\
\hline WRONG & & & 2 & 1 & & & 1 & & & & & \\
\hline UNDERSTAND & 1 & & 1 & 1 & 4 & 1 & 3 & 3 & & 2 & 2 & \\
\hline Total & 35 & 36 & 37 & 35 & 32 & 30 & 20 & 14 & 34 & 19 & 29 & 26 \\
\hline
\end{tabular}




\section{Appendix D - Atypical Conjunctive Devices}

The following are examples of conjunctive devices or discourse markers, in bold, that were used by the interpreters that were not described in the literature but were included in this study.

Alice - DURING THAT TWO, THREE YEAR, ME WORK WITH BILL...

Adam - TIME-PASSES/EVENTUALLY, TEST, DAY, YESTERDAY NIGHT ME, THERE HOME STUDY, CHECK ++

Adam - NOW ME INFORM-YOU STORY, HOW ME LEARN ASL, BEFORE ME TEEN, SMALL, GROWUP LEARN++NEXT HOW ME START INTERPRET

Bea - BEFORE INTERPRETER SEARCH PLENTY MANY, MEET++ SHOWME++, ADVISE-THEM, ADVISE-ME , FEW THEY++.LEARN++ HOW? PUSH-LEFT KNOW-THAT TWO YEARS PICKUP++ SIGN-ASL, IMPROVE

Bea - ADD, BILL DEAD, WHEN? AGE 78

Carol - FROM-THEN-ON TWO YEARS, PICKUP++ SIGN-ASL, DEVELOP, GOOD GOOD

Denise - EXAMPLE, MY FOURTH ASL CLASS ME TOOKUP

Denise - SUPPOSE MY PARENTS DEAF, ME GROW-UP LEARN ASL, WILL. THAT ME, NO. INSTEAD ME LEARN HOW? HAVE DIFFERENT++ ASL TEACHERS, SIGN-ASL

Denise - WRONG, SISTER STOLE, NO++ LATER+ ME FOUND TAPE, PUT-IN MY VCR, BLAME-ME

Francine - POINT (back to the point of my story), DEAF SERVICE SUPPORT, SUMMON-ME , GO SIT-ACROSS, INTERVIEW 